\title{
Serum Total Bilirubin levels in Diabetic Retinopathy - A case control study
}

\author{
Dr. Prabhavathi.K ${ }^{1}$, Mrs. Mamatha Kunder ${ }^{2}$, Dr. Shashidhar K.N ${ }^{3}$, \\ Dr. Harish $\mathrm{R}^{4}$. \\ Asst Professor ${ }^{1}$, Lecturer ${ }^{2}$, Professor \& HOD ${ }^{3}$, Post graduate student ${ }^{4}$. \\ Dept of Biochemistry, Sri Devaraj Urs Medical College, Kolar.
}

\begin{abstract}
ABTRACT: Introduction/ Back ground
Diabetic retinopathy (DR), ending with loss of vision is one of the microvascular complications of Diabetes Mellitus (DM). Bilirubin, with potent antioxidant and anti-inflammatory properties on the vasculature, has been linked to vaso-occlusive disorders.

Objectives

To evaluate the Serum Total Bilirubin levels in diabetic patients with retinopathy, diabetic without complications \& to compare and correlate the same parameters with age \& gender matched clinically healthy controls.
\end{abstract}

\section{Materials and Methods}

Study group consisted, total of 75 subjects divided into three groups - Group I (DR), Group II (Type 2 DM without retinopathy) \& Group III (clinically proven healthy controls). Estimation of Biochemical parameters were done by standard methods.

\section{Results}

Comparison of biochemical parameters were made between the three groups. We observed significant increase in FBS, $\mathrm{HbA}_{1} \mathrm{c}$ \& significant decrease in serum Total Bilirubin with p value $<0.001$ in Group I when compared to Group II \& Group III. Negative correlations of Total Bilirubin with FBS \& with HbA $A_{1}$ were observed in Group I.

\section{Conclusion}

Poor Glycemic control, oxidative stress in diabetes can cause profound damage to the vital organs. Negative association of Serum Total Bilirubin with FBS \& HbA ${ }_{1} c$ in Group I \& Group II when compared to Group III. Therefore estimation of Serum Total Bilirubin is a less expensive parameter, which helps clinicians in effectively controlling and preventing the onset \& progression of complications of diabetes such as diabetic retinopathy.

Key Words: Diabetes mellitus, Diabetic Retinopathy, $F B S, H b A_{l} c$, serum Total Bilirubin

\section{INTRODUCTION}

Diabetes Mellitus is a complex metabolic disease, primarily characterized by hyperglycemia, caused by variable interactions between hereditary and environmental factors [1]. Diabetes is the major health problem in India. India with 180 Million population, 15 Million are known to be with Type 2 Diabetes mellitus (T2DM) [2]. According to WHO estimation for prevalence of T2DM, it is in the fifth position worldwide \& by the year 2030 , it is expected to occupy second place (2). T2DM comprises an array of metabolic dysfunctions associated with an increased incidence of microvascular and macrovascular complications [3], which are the major causes of morbidity and mortality [1]. Hyperglycemia is the most important factor at the onset \& if not controlled leads to various biochemical disorders such as hyperlipidemia and oxidative stress [4]. The biochemical derangements in both T1DM \& T2DM further leads to various vascular complications. To name a few, nephropathy, retinopathy, neuropathy and atherosclerosis [5]. Diabetic Retinopathy (DR) is one of the common microvascular complications of T2DM, leading to impaired or total loss of vision [6]. DR is estimated to account for nearly 5\% of all global blindness [7]. The duration of DM, hyperglycemia, hypertension \& hyperlipidemia have shown to be the known and well established risk factors for DR, primarily the microvascular injury. Bilirubin, a major intravascular product of heme catabolism is traditionally considered as a toxic waste product. However, in 1937, Najib - Farah first postulated possible protective actions of Bilirubin thus, it gained the momentum as a potent antioxidant and anti-inflammatory factor on the vasculature and has been linked to vaso-occlusive disorders [7,8]. Previous studies have shown that elevated serum Bilirubin levels provide protection against 
cardiovascular disease, stroke \& peripheral arterial disease $[9,10]$. This created an interest in us to hypothesize in rural population that, whether high Serum Total Bilirubin levels within the physiological range has a decreased risk of development of retinal complications in T2DM.

\section{AIMS \& OBJECTIVES}

To evaluate, compare \& correlate the Serum Total Bilirubin levels, with other traditional liver function tests, renal parameters, FBS \& HbA1c in T2DM with retinopathy, T2DM without complications \& clinically proven healthy age \& gender matched controls.

\section{MATERIALS AND METHODS}

Ours is a case control study, conducted at R L Jalappa Hospital, a rural tertiary care referral hospital, attached to Sri Devaraj Urs Medical College, Kolar, Karnataka over a period of 6 months from April 2013 to September 2013. Study was approved by Institutional ethical clearance and a written informed consent was obtained from all the participants.

Present study included a total of seventy five individuals, with age group of 30-70 years of either gender attending Ophthalmology OPD, R.L.Jalappa Hospital and Research Center, Kolar.

Group I: Twenty five clinically proven cases of T2DM with retinopathy based on fundoscopic changes.

Group II: Twenty five T2DM subjects without retinopathy changes based on fundoscopic examination.

Group III: Twenty five age \& gender matched clinically proven healthy individuals.

Non diabetic cases presenting with retinopathy of whatever cause and any subject with recent history of fever, infection and chronic illness like cancer, Chronic Obstructive Pulmonary Disease, Liver diseases, cardiac diseases, stroke, gestational diabetes mellitus and complications related to diabetes like ulcers, neuropathy, nephropathy \& any subject receiving antioxidant therapies were excluded from our study.

After $8 \mathrm{hrs}$ of informed fasting, $6 \mathrm{ml}$ of venous blood was drawn from themedian cubital vein of right forearm in supine position in both study and control groups under complete aseptic precautions. Care was taken throught the procedure that samples were not haemolysed. During sample collection standard protocol was followed, beginning from reception of the patient, tying of tourniquet, drawing of blood etc.,precautions were taken in such a way that sample hemolysis was prevented and to confirm that Bilirubin values during the analysis were not altered. Even for other parameters because of the standard protocol preanalytical errors were avoided. Estimation of Blood Glucose [11], Blood Urea [12],Serum Creatinine [12] \& Liver Function Test $[13,14]$ were done by Standard methods using Dry chemistry Vitros 250 Johnson \& Johnson analyzer, which works on the principle reflectance photometry.Routine chemistries were estimated in the serum. IQAS was confirmed before any parameter assay. Sample rerun was done in case of doubtful or absolute necessary. Monthly EQAS was done to reconfirm the values and all the parameters were within \pm 1SD.This was reassured with monthly BIO-RAD EQAS report. Both IQAS \& EQAS was done using BIORAD third party controls. Glycated Hemoglobin [11] was analyzed in the whole blood by HPLC method using BIORAD D-10. Hemoglobinopathies were confirmed \& rejected. In addition rejection criteria were strictly followed for each parameter to confirm quality assurance of the parameters.

\section{STATISTICAL ANALYSIS}

Data collected was tabulated and descriptive statistical tools, mean and standard deviations were calculated. ANOVA test was used for testing significance by applying SPSS software evaluatory version 14. When difference was found Post-Hoc Bonferroni criterion was used. The mean difference was defined as significant at $\mathrm{p}<0.05$ level and correlation of parameters were done by using Pearson's formula. The percentage of significance was obtained on the basis of ' $r$ ' values and ' $p$ ' values.

\section{RESULTS}

The baseline characteristics of our present study population are shown in Table 1 . Among the 25 subjects in Group I, 16 were males \& 9 were females, in Group II, 18 were males \& 7 were females \& in Group III, 15 were males \& 10 were females. The age group was between 30-70 years. The mean age in Group I, Group II and Group III showed no statistical significant "p" value. The mean duration of diabetes mellitus in Group I \& in Group II showed statistically significant "p" value $<0.05$ and as mentioned before Group III were Age \& gender matched non diabetic, clinically healthy controls. One way analysis of variance showed that FBS, HbA1c, Total Bilirubin \& Direct Bilirubin were highly significant with $\mathrm{p}<0.001$. Post Hoc analysis using Bonferroni criterion for significance indicated that Group I Vs Group II, FBS, HbA1c, Total Bilirubin \& Direct Bilirubin were highly significant with $\mathrm{p}<0.001$. When Group II Vs Group III was compared, FBS, Total Bilirubin \& Direct Bilirubin showed significant $\mathrm{p}$ value $<0.05$, whereas HbA1c showed highly significant $\mathrm{p}$ value $<0.001$. On 
comparison between Group I Vs Group III, One way ANOVA showed that FBS, HbA1c \& Total Bilirubin were highly significant, with $p$ value $<0.001$, whereas Direct Bilirubin was significant with $p$ value $<0.05$ (Table 3 ).

Correlation of Total Bilirubin with $\mathrm{HbA}_{1} \mathrm{C}$ and FBS in Diabetics with retinopathy: In Diabetic Retinopathy group, negative correlation of Total Bilirubin with FBS $(r=-0.131) \& \mathrm{HbA}_{1} \mathrm{C}(\mathrm{r}=-0.378)$ were observed (Fig 1).

Correlation of Total Bilirubin with $\mathrm{HbA}_{1} \mathrm{C}$ and FBS in Diabetics without retinopathy: In Diabetes Mellitus group, when Total Bilirubin with FBS $(r=-0.094) \&$ Total Bilirubin with $\mathrm{HbA}_{1} \mathrm{C}(\mathrm{r}=-0.375)$ were correlated, a negative association was observed (Fig 2).

\section{DISCUSSION:}

Diabetes mellitus, a metabolic disorder is the leading cause of Retinopathy, designated as Diabetic Retinopathy \& one of the major microvascular complications ending with acquired blindness [15]. It is due to microangiopathy affecting the retinal arterioles, capillaries and venules. Damage is caused by both microvascular leakage and occlusion. A series of risk factors have been related to the development and progression of retinopathy in diabetic patients to name a few, longer duration of diabetes, aging, Hyperglycemia and Hyperlipidemia [7].

Our present study, concentrated on the gender distribution. We observed that the number of males were higher with DM \& DR when compared to the females. Ours findings were consistent to the studies conducted by Rema M, etal., Harris M I, etal., \& Dandona L, etal., on diabetic retinopathy [16,17,18]. Study done by Aiello LM etal., reported female preponderance over males [19]. The present study showed that as the duration of diabetes mellitus increases, there is increase in the incidence and progression of retinopathy (Table 1).

In our study, FBS and $\mathrm{HbA}_{1} \mathrm{c}$ levels were significantly increased in Group I and Group II when compared to Group III (Table2), which is on par with studies done by Zelia Maria da silvacorrea and his co workers [1] \& Ishrat Kareem and his coworkers [20]. Hyperglycemia-induced vascular injury leads to increased glucose flux through the polyol pathway, resulting in cellular damage, thereby resulting in the various microvascular and macrovascular complications [21]. $\mathrm{HbA}_{1} \mathrm{c}$ is also shown to have a special affinity for oxygen thereby causes tissue anoxia and plays a role in causation of micro and macroangiopathy.

Bilirubin a metabolic end product of heme degradation is considered as a toxic substance with adverse effects such as jaundice is not clear. However, Recent studies have suggested that elevated serum Total Bilirubin may provide protection against stroke, cardiovascular disease and peripheral vascular disease [7,22,9]. Our study, showed significantly decreased levels of serum Total Bilirubin in Group I as well as in Group II when compared to Group III. The probable mechanism underlying this protective action of Bilirubin is through its antioxidant action, anti-inflammatory effects on the vasculature and cytoprotective properties. Oxidative stress \& inflammation are considered as crucial factors in the pathogenesis of DR. Oxidative stress induced biochemical changes contribute to both functional \& structural changes in the retinal microvasculature. Therefore, it is possible that an increase in serum Total Bilirubin level inhibits oxidative stress and inflammation processes, thus interrupting the pathways leading to the development of DR [22]. These findings support the notion that "people with high serum Total Bilirubin levels, are protective against the development of microvascular complications of DM like DR".

In our study, serum Total Bilirubin levels has negative correlation with FBS \& HbA1C.This data is consistent with studies conducted by shichiri M, etal., UK Prospective Diabetes study Group \& Ohnaka K, etal.,[23,24,25]. This can be due to (i) Bilirubin may inhibit the glycation of $\mathrm{Hb}$ by reducing oxidative stress. Sugars react non-enzymatically with a wide range of proteins to form early glycation products and oxidative stress is involved in the glycation reaction. Oxidative stress can facilitate the autoxidation of glucose to dicarbonyl intermediates, which is an early step in Millards reaction [23]. In addition malondialdehyde, which is generated by lipid oxidation, is thought to enhance the process of protein glycation by acting as an anchor between sugar \& $\mathrm{Hb}$ moieties [26]. (ii) Bilirubin may play an important role in Glycemic control. Increased expression of heme oxygenase-1, is responsible for the conversion of $\mathrm{Hb}$ to Bilirubin, which is associated with enhanced insulin sensitivity \& glucose metabolism [9].

In our study we also estimated other Liver function test such as SGOT, SGPT, Alkaline Phosphatase, Total proteins, Albumin, GGT \& Renal fuction test (Urea, Creatinine). We did not observe any significant differences among them. However, study conducted by Ossama Haddad etal., showed high levels of Urea, Creatinine, which were also associated with an increased risk for any grade of diabetic retinopathy [27]. 


\section{CONCLUSION}

Poor Glycemic control, oxidative stress in diabetes can cause profound damage to the vital organs in the body. We observed negative association of Serum Total Bilirubin with FBS \& $\mathrm{HbA}_{1} \mathrm{c}$ in Group I \& Group II when compared to Group III. Bilirubin, with potent antioxidant and anti-inflammatory properties on the vasculature, has been linked to vaso-occlusive disorders. Hence we hypothesized that high Serum Total Bilirubin within the physiological range may have a decreased risk of development of retinal complications in diabetes mellitus, unless otherwise if any associated hepatic or renal disease.

Therefore estimation of Serum Total Bilirubin is a less expensive tool, which helps clinicians in effectively controlling and preventing the onset \& progression of complications of diabetes such as diabetic retinopathy.

\section{Our study has some limitation,}

\section{LIMITATION}

1. We could not analyze the parameters related to insulin resistance,

2. No data collected regarding medications affecting liver function / Bilirubin levels,

3. Study has been conducted in Kolar population - so whether these findings can be applied to other ethnic groups has to be considered and

4. Study was done in a smaller size population-so further studies with a larger sample size, is required to confirm these findings.

\section{REFERENCES}

[1]. Correa ZMS, Freitas AM, Marcon IM. Risk factors related to the severity of diabetic retinopathy. Arq Bras Oftalmol. 2003; 66:739743.

[2]. Suresh BabuK,AravindKumar.R, Anand Shaker I. Glycated albumin and Microalbuminuria as risk factors in Diabetic retinopathy of type 2 Diabetes mellitus.Journal of Biological \& Scientific opinion 2013;1.

[3]. Nikolaos P, Stella S, Despina Perrea, Christos D. Matrixmetalloproteinases and diabetic vascular complications. Angiology march/april 2005; 56: 2173-2189.

[4]. Mossad A, Abd-Allah Youssef. Evaluation of some biochemical changes in diabetic patients. Clinica Chimica Acta. 2004; 346: 161170.

[5]. V.Jakus, N. Reitbrock. Advanced glycation end products \& the progress of diabetic vascular complications.Physiol. Res. 2004; 53: $131-142$

[6]. M. Porta, A-k Sjoelie, N Chaturvedi, L Stevens, R Rottiers, M Vegilo et al. Risk factorsfor progression to proliferative diabetic retinopathy in the EURODIAB Prospective Complication Study. Diabetologia 2001;44: 2203-2209.

[7]. Ho Chan Cho.The relationship among Homocysteine, Bilirubin and Diabetic retinopathy. Diabetes metab J 2011; 35: 595-601

[8]. SeungSeok Han, Ki Young Na, Dong- Wan Chae, Yon Su Kim, Suhnggwon Kim and Ho Jun Chin. High Serum Total Bilirubin Is Associated With The Reduced Risk Of Diabetes Mellitus \& Diabetic Nephropathy. Tohoku J. Exp. Med 2010; 221:133-140.

[9]. Cheriyath P, Gorrepati VS, Peters I, Nookala V, Murphy ME, SroujiN,Fischman D. High total bilirubin as a protective factor for diabetes mellitus:An analysis of NHANES data from 1999-2006. J Clin Med Res 2010;2: 201-206.

[10]. Michiaki Fukui, Muhei Tanaka, Emi Shiraishi, Ichiko Harusato, Hiroko Hosoda, Mai Asano et.al. Relationship between serum Bilirubin and albuminuria in patients with type 2 Diabetes. Kidney international 2008; 74:1197-1201.

[11]. David B Sacks MB. Estimation of Blood Glucose and Glycated Haemoglobin in. Carl A Burtis, Edward R Ashwood and David E Bruns, Tietz text book of Clinical Chemistry 4th ed, Saunder New Delhi : Elsevier Co., 2006;870-884.

[12]. Edmund Lamb, David J, Cristopher P. Estimation of Creatinine and Urea. in. Carl A Burtis, Edward R Ashwood and David E Bruns, Tietz text book of Clinical Chemistry 4th ed, Saunders. New Delhi: Elsevier Co., 2006; 798-803.

[13]. Panteghini M, Bais R and Van soling WW. Enzymes in. Carl A Burtis, Edward R Ashwood and David E Bruns, Tietz text book of Clinical Chemistry 4th ed, Saunders. New Delhi: Elsevier Co.2006; 604-613.

[14]. Higgins T, Beutler E and Doumas BT. Estimation of Serum Bilirubin. in. Carl A Burtis, Edward R Ashwood and David E Bruns, Tietz text book of Clinical Chemistry 4th ed, Saunders. New Delhi: Elsevier Co., 2006; 1195-1197.

[15]. Rema M, Pradeepa R. Diabetic Retinopahty: An Indian perspective. Indian J Med Res. 2007; 125:297- 310.

[16]. Rema M, Premkumar S, Anitha B, Deepa R, Pradeepa R, Mohan V. Prevalence of diabetic retinopathy in urban India: The Chennai Urban Rural Epidemiology Study (CURES) eye study, I. Invest Ophthalmol Vis Sci 2005; 46:2328-2333.

[17]. Harris MI, Klein R, Welborn TA, Knuiman MW. Onset of NIDDM occurs at least 4-7 years before Clinical diagnosis. Diabetes Care. 1992; 15:815-819.

[18]. Dandona L, Dandona R, Naduvilath TJ, Mc Carty CA, Rao GN. Population based assessment of diabetic retinopathy in an urban population in southern India. Br J Opthal. 1999; 83 : 937- 40.

[19]. Aiello LM, Rand LI, Briones JC, Wafai MZ, Sebestyen JG. Diabetic retinopathy in Joslin Clinic patients with adult onsetdiabetes. Opthalmology 1981; 88:619-623.

[20]. Kareem I, Jaweed SA, Bardapurkar JS, Patil VP. 'Study of magnesium, glycosylated hemoglobin and lipid profile in Diabetic Retinopathy. Indian J Clin Biochem.2004; 19:124-127.

[21]. Service FJ, O’Brien PC. The relation of glycemia to the risk of development and progression of retinopathy in the Diabetic control and complication trial. Diabetologia 2001; 44:1215-1220.

[22]. MihoYasuda,Yutaka Kiyohara, Jie Jin Wang, Satoshi Arakawa, Koji Yonemoto, Yasufumi Doietal,. High serum Bilirubin levels and Diabetic retinopathy. Ophthalmology 2011; 118:1423-1428.

[23]. Shichiri M, Kishikawa H, Ohkubo Y, Wake N. Long-term results of the Kumamoto study on optimal diabetes control in type 2 diabetic patients. Diabetes Care 2000; 23 Suppl 2: B21-29.

[24]. UK Prospective Diabetes Study (UKPDS) Group. Intensive blood-glucose control with sulphonylureas or insulin compared with conventionaltreatment and risk of complications in patients with type 2 diabetes (UKPDS 33). Lancet 1998;352: 837-853.

[25]. Ohnaka K, Kono S, Inoguchi T, Yin G, Morita M, Adachi M, Kawate H,Takayanagi R. Inverse associations of serum bilirubin with high sensitivity C-reactive protein, glycated hemoglobin, and prevalence of type 2 diabetesin middle-aged and elderly Japanese men and women. Diabetes Res Clin Pract 2010; 88: 103-110. 
[26]. Vitek L, Jirsa M, Brodanova M, Kalab M, Marecek Z, Danzig V, NovotnyL, Kotal P. Gilbert syndrome and ischemic heart disease: a protective effectof elevated bilirubin levels. Atherosclerosis 2002; 160: 449-456.

[27]. Haddad A W El Ossama,Saad M K .Prevalence and risk factors for diabetic retinopathy among Omani diabetics.Br J Ophthalmol 1998; 82: 901-906.

Results

Table 1: Baseline characteristics of study groups

\begin{tabular}{|l|l|l|l|l|}
\hline Groups & $\begin{array}{l}\text { Group I } \\
\mathrm{n}=25\end{array}$ & $\begin{array}{l}\text { Group II } \\
\mathrm{n}=25\end{array}$ & $\begin{array}{l}\text { Group III } \\
\mathrm{n}=25\end{array}$ & Significance \\
\hline $\begin{array}{l}\text { Mean age(yrs) } \\
\text { (Mean } \pm \text { SD) }\end{array}$ & $52.84 \pm 9.57$ & $53.24 \pm 9.82$ & $\mathrm{p}>0.05$ & \\
\hline $\begin{array}{l}\text { Duration of DM(yrs) } \\
\text { Mean } \pm \text { SD) }\end{array}$ & $9.16 \pm 4.91$ & $6.48 \pm 3.3$ & --46 & $\mathrm{p}<0.05$ \\
\end{tabular}

Group I :T2DM with DR, Group II: T2DM without DR \& Group III: Clinically proven healthy controls.

Table 2: ANOVA results comparing FBS, HbA1c, Liver function test, Renal function test in Group I (T2DM with DR), Group II (T2DM without DR) \& Group III (Clinically proven healthy controls).

\begin{tabular}{|c|c|c|c|c|}
\hline Parameters & Group I & Group II & Group III & $\begin{array}{l}\text { ANOVA- F-value with } \\
\text { significance }\end{array}$ \\
\hline FBS (mg/dl) & $172.76 \pm 86.16$ & $111.16 \pm 24.94$ & $96.76 \pm 12.54$ & $\begin{array}{l}14.897 \\
\mathrm{p}<0.001 *\end{array}$ \\
\hline HbA1c \% & $9.42 \pm 1.58$ & $7.74 \pm 0.96$ & $5.53 \pm 0.66$ & $\begin{array}{l}73.428 \\
p<0.001 *\end{array}$ \\
\hline Total Bilirubin (mg/dl) & $0.48 \pm 0.12$ & $0.75 \pm 0.09$ & $0.9 \pm 0.25$ & $\begin{array}{l}37.310 \\
\mathrm{p}<0.001 *\end{array}$ \\
\hline Direct Bilirubin (mg/dl) & $0.14 \pm 0.04$ & $0.25 \pm 0.15$ & $0.24 \pm 0.14$ & $\begin{array}{l}6.116 \\
\mathrm{p}<0.001 *\end{array}$ \\
\hline AST (IU/L) & $31 \pm 7.07$ & $28.64 \pm 7.6$ & $32.2 \pm 8.85$ & $\begin{array}{l}1.321 \\
p=0.273\end{array}$ \\
\hline ALT(IU/L) & $32.56 \pm 8.12$ & $30.88 \pm 6.01$ & $34 \pm 5.81$ & $\begin{array}{l}1.344 \\
p=0.267\end{array}$ \\
\hline ALKP(IU/L) & $119.76 \pm 53.44$ & $105.72 \pm 34.82$ & $141.16 \pm 181.65$ & $\begin{array}{l}0.644 \\
p=0.528\end{array}$ \\
\hline Total protein $(\mathrm{g} / \mathrm{dl})$ & $6.94 \pm 0.63$ & $7.05 \pm 0.75$ & $7.34 \pm 0.7$ & $\begin{array}{l}2.162 \\
p=0.122\end{array}$ \\
\hline Albumin (g/dl) & $3.8 \pm 0.35$ & $3.98 \pm 0.43$ & $3.85 \pm 0.53$ & $\begin{array}{l}1.084 \\
p=0.344\end{array}$ \\
\hline Globulin (g/dl) & $3.13 \pm 0.45$ & $3.07 \pm 0.5$ & $3.41 \pm 0.6$ & $\begin{array}{l}2.985 \\
p=0.067\end{array}$ \\
\hline $\mathrm{A} / \mathrm{G}$ ratio & $1.21 \pm 0.19$ & $1.16 \pm 0.31$ & $1.28 \pm 0.19$ & $\begin{array}{l}1.587 \\
\mathrm{p}=0.212\end{array}$ \\
\hline GGT (IU/L) & $26.84 \pm 9.06$ & $27.88 \pm 8.51$ & $31.48 \pm 11.97$ & $\begin{array}{l}1.492 \\
p=0.232\end{array}$ \\
\hline Blood urea (mg/dl) & $28.84 \pm 7.6$ & $25.1 \pm 7.49$ & $27.56 \pm 8.31$ & $\begin{array}{l}1.420 \\
p=0.248\end{array}$ \\
\hline Serum creatinine $(\mathrm{mg} / \mathrm{dl})$ & $0.83 \pm 0.3$ & $0.88 \pm 0.18$ & $0.84 \pm 0.23$ & $\begin{array}{l}0.308 \\
\mathrm{p}=0.736\end{array}$ \\
\hline
\end{tabular}

$* p$ value $<0.05$ is significant

Table 3: Post HOC (BONFERRONI TEST) comparing means of FBS, HbA1c, Total Bilirubin \& Direct Bilirubin in Group I (T2DM with DR), Group II (T2DM without DR) \& Group III (Clinically proven healthy controls). 


\begin{tabular}{|l|l|l|l|l|}
\hline & $\begin{array}{l}\text { FBS } \\
\text { (mg/dl) }\end{array}$ & HbA1c\% & $\begin{array}{l}\text { T. Bilirubin } \\
\text { (mg/d) }\end{array}$ & $\begin{array}{l}\text { D. Bilinubin } \\
\text { (mg/dl) }\end{array}$ \\
\hline $\begin{array}{l}\text { Group I } \\
\text { Vs } \\
\text { Group II }\end{array}$ & $\mathrm{p}<0.001$ & $\mathrm{p}<0.001$ & $\mathrm{p}<0.001$ & $\mathrm{p}<0.001$ \\
\hline $\begin{array}{l}\text { Group II } \\
\text { Vs } \\
\text { Group III }\end{array}$ & $\mathrm{p}<0.05$ & $\mathrm{p}<0.001$ & $\mathrm{p}<0.05$ & $\mathrm{p}<0.05$ \\
\hline $\begin{array}{l}\text { Group I } \\
\text { Vs } \\
\text { Group III }\end{array}$ & $\mathrm{p}<0.001$ & $\mathrm{p}<0.001$ & $\mathrm{p}<0.001$ & $\mathrm{p}<0.05$ \\
\hline
\end{tabular}
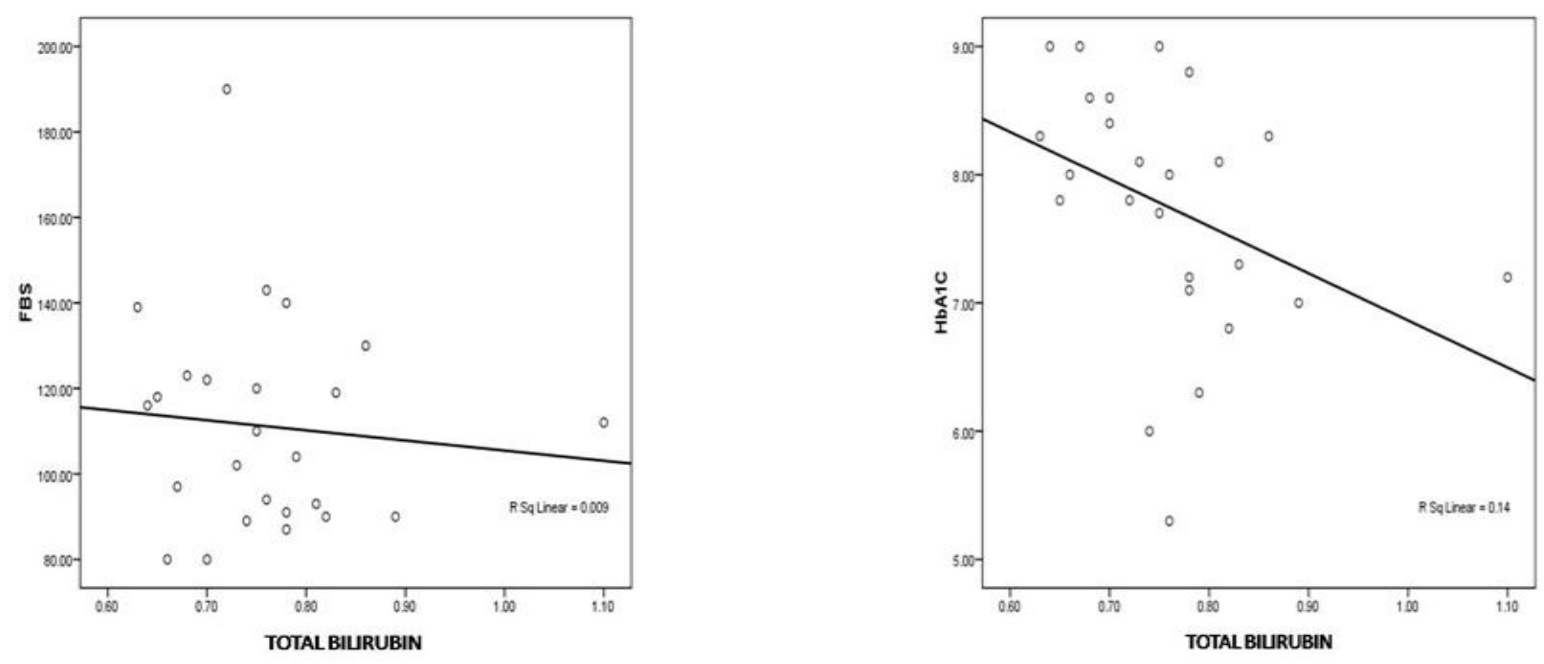

Fig 1: Correlation of Total Bilirubin with $\mathrm{FBS}$ and $\mathrm{HbA}_{1} \mathrm{C}$ in Diabetics with retinopathy
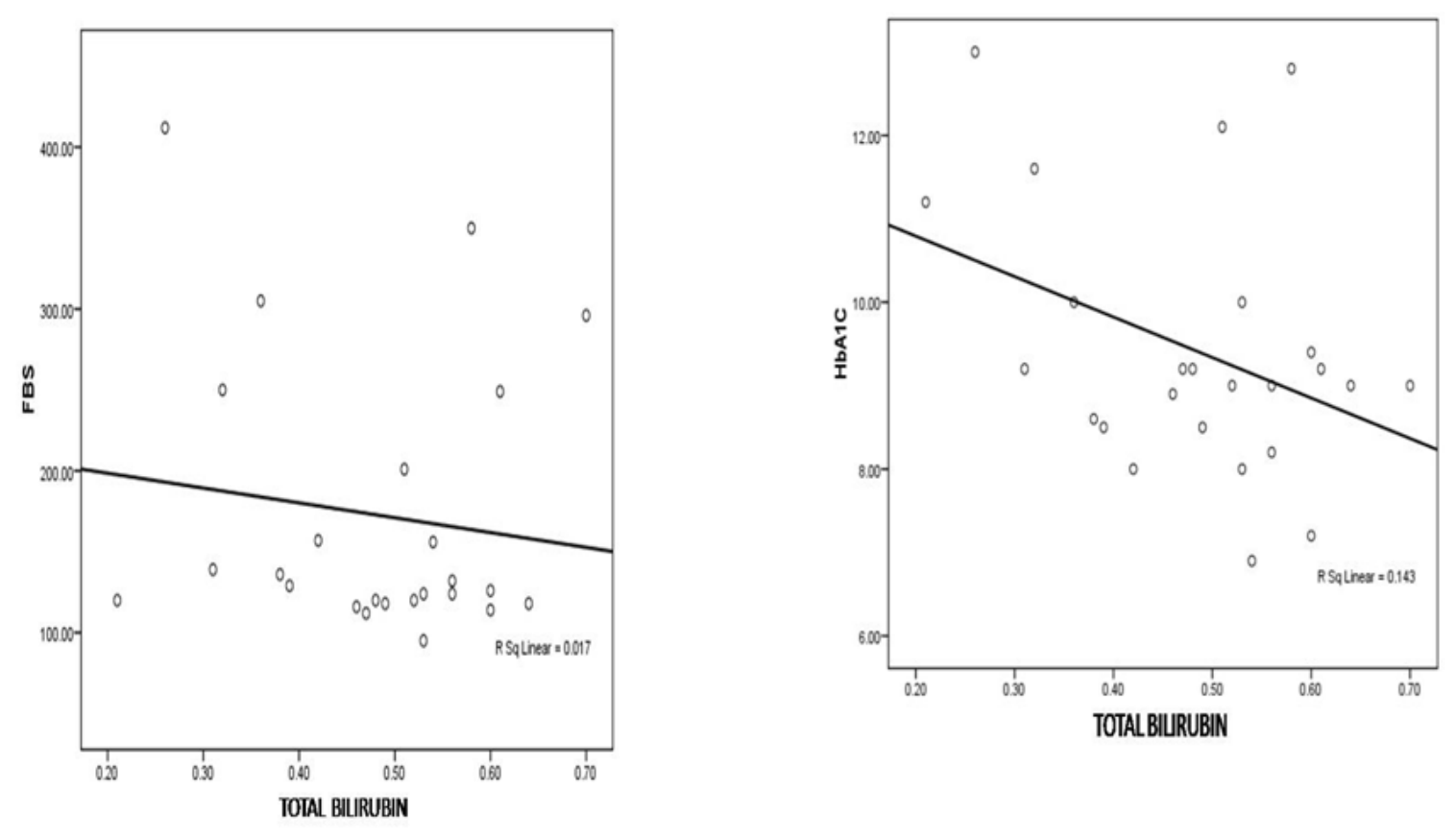

Fig 2: Correlation of Total Bilirubin with $\mathrm{FBS}$ and $\mathrm{HbA}_{1} \mathrm{C}$ in Diabetics without retinopathy 